\title{
La travesía del batallón Socorro en la Campaña del Sur: legado de un batallón provincial en las guerras de Independencia de la Nueva Granada (1813-1816)*
}

\section{Resumen}

En el marco de la conmemoración del bicentenario de la Independencia de Colombia, este artículo tiene por objeto profundizar sobre la trayectoria del batallón Socorro que desarrolló sus operaciones entre 1813 y 1816 en la campaña dirigida a expulsar los españoles de las provincias del sur de la Nueva Granada y a la defensa del epicentro del poder republicano tras la llegada del ejército expedicionario español. La metodología aplicada comprendió un estudio descriptivo y cualitativo realizado con base en la consulta de fuentes primarias de este periodo. Este batallón, de origen provincial, emprendió su accionar en medio de un ambiente de polarización política interna y, a pesar de todas las vicisitudes de la guerra, sirvió de base para el paso de fuerzas milicianas a veteranas, aspecto que sería clave dentro del proceso de formalización y profesionalización de las tropas republicanas con las cuales fue posible culminar la liberación del territorio neogranadino.

\section{Palabras clave}

Tesauro: Historia, Colombia, guerra, independencia, ejército.

Referencia bibliográfica para citar este artículo: Pita Rico, Roger. "La travesía del batallón Socorro en la Campaña del Sur: legado de un batallón provincial en las guerras de Independencia de la Nueva Granada (1813-1816)". Anuario de Historia Regional y de las Fronteras 25.2 (2020): 277-305.

Fecha de recepción: 30/07/2019

Fecha de aceptación: 3/01/2020

Roger Pita Pico: Magister en Estudios Políticos de la Pontificia Universidad Javeriana. Especialista en Política Social y en Gobierno Municipal de la Pontificia Universidad Javeriana. Director de la Biblioteca Eduardo Santos de la Academia Colombiana de Historia. Código ORCID: 0000-0001-9937-0228. Correo electrónico: rogpitc@hotmail.com.

\footnotetext{
*El presente artículo hace parte de un proyecto de investigación que de manera independiente adelanta el autor sobre Reclutamiento y formación de los Ejércitos republicanos durante las guerras de Independencia de Colombia, 1810-1822.
} 


\title{
The Crossing of the Socorro Battalion in the Southern Campaign: Legacy of a Provincial Battalion in the Wars of Independence of New Granada (1813-1816)
}

\begin{abstract}
In the framework of the commemoration of the bicentennial of the Independence of Colombia, this article aims to analyze the trajectory of the Socorro battalion which developed its operations between 1813 and 1816 in the campaign that had the purpose of expelling the Spaniards from the southern provinces of the New Granada and defend the epicenter of republican power after the arrival of the Spanish expeditionary army. The methodology applied included a descriptive and qualitative study carried out based on the consultation of primary sources of this period. This battalion, of provincial origin, developed its action in the midst of an environment of internal political polarization and, despite all the vicissitudes of the war, served as the basis for the passage of militia forces to veterans, an aspect that would be key in the process of formalization and professionalization of the republican troops with which it was possible to complete the liberation of the Nueva Granada territory.
\end{abstract}

Keywords

Thesaurus: History, Colombia, War, Independence, Army.

\section{A travessia do batalhão de Socorro na Campanha do Sul, legado de um batalhão provincial nas guerras da independência de Nova Granada (1813-1816)}

\section{Resumo}

No marco da comemoração do bicentenário da Independência da Colômbia, este artigo tem como objetivo analisar a trajetória do batalhão Socorro que desenvolveu suas operações entre 1813 e 1816 na campanha destinada a expulsar os espanhóis das províncias do sul do Novo Granada e defender o epicentro do poder republicano após a chegada do exército expedicionário espanhol. A metodologia aplicada incluiu um estudo descritivo e qualitativo baseado na consulta de fontes primárias deste período. Este batalhão, de origem provincial, desenvolveu suas ações em um ambiente de polarização política interna e, apesar de todas as vicissitudes da guerra, serviu de base para a passagem das forças milicianas aos veteranos, aspecto que seria fundamental dentro do processo de formalização e profissionalização das tropas republicanas com o qual foi possivel culminar a libertação do território neogranadense.

Palavras-chave

Tesauro: História, Colombia, guerra, independência, exército. 


\section{Introducción}

La primera fase republicana del proceso de Independencia en la Nueva Granada se inauguró en 1810 con las primeras manifestaciones de autonomía política expresadas a través de la instalación de varias Juntas de Gobierno. El 27 de noviembre de 1811 fue creada la Federación de las Provincias Unidas conformada por las provincias de Antioquia, Cartagena, Neiva, Pamplona y Tunja. Sin embargo, a esta integración de corte federalista se opusieron desde Bogotá los centralistas que al mando del general Antonio Nariño establecieron lo que se denominó Estado de Cundinamarca y lo cual desató, desde finales de 1812, una lucha interna por el poder, en torno a la forma de organización del naciente Estado.

Esa fragmentación del poder y enfrentamiento interno entre facciones republicanas ${ }^{1}$ se convirtió en un punto de debilidad en los anhelos por consolidar una nueva nación independiente. Paralelamente a estas disputas políticas acentuadas por las rivalidades entre provincias, se desarrollaban acciones militares dirigidas a derribar la resistencia realista que permanecía activa en las provincias de Santa Marta, Popayán y Pasto. En estas zonas la guerra fue intermitente pues ni las fuerzas patriotas ni las españolas lograron triunfos absolutos.

La historia oficial y los relatos de los cronistas de la guerra sobre la confrontación militar vivida en esa primera fase republicana se dedicaron más que todo a exaltar el heroísmo de los mártires de Cartagena y a remarcar los errores y desaciertos de la tropa y de los oficiales patriotas que sucumbieron ante las fuerzas de Reconquista. Trabajos recientes como el del historiador Luis Rubén Pérez Pinzón han hecho énfasis en trazar una nueva mirada que permite ver la complejidad misma de la guerra al retomar el caso de la batalla de Cachirí que no ha sido rememorada en su real dimensión como el primer combate de resistencia del ejército patriota. ${ }^{2}$

Ampliamente reconocido es el aporte de la provincia del Socorro $^{3}$ desde los tiempos de este interregno republicano a la causa de la Independencia. ${ }^{4}$ La constancia y lealtad hacia la causa patriota fueron características que distinguieron a las gentes

\footnotetext{
${ }^{1}$ Anthony McFarlane, "La fragmentación del orden político: la "Primera República” en la Nueva Granada, 1810-1815”, Historia y Sociedad 8 (2002): 73.

${ }^{2}$ Luis Rubén Pérez Pinzón, "Tergiversaciones sobre la batalla de Cachirí y el restablecimiento del régimen virreinal neogranadino (1816)", Historia y Memoria 15 (2017): 80-81.

${ }^{3}$ Desde el siglo XVIII, la provincia de El Socorro se consolidó como uno de los epicentros más prósperos de la Nueva Granada, cuyas principales actividades económicas eran la agricultura y la producción de lienzos. Su posición estratégica y su cercanía al camino real la convirtieron en un punto nodal dentro del circuito comercial regional. Esta serie de factores y el intenso poblamiento blanco-mestizo incidieron en el aumento poblacional pues de 4.000 habitantes registrados en 1711 se pasó a un total de 33.710 habitantes en el censo de 1778. John Phelan, El pueblo y el Rey. Revolución Comunera en Colombia, 1781 (Bogotá: Carlos Valencia editores, 1980), 57.

${ }^{4}$ Según algunos cálculos, fueron más de 10.000 los soldados oriundos de la provincia del Socorro que defendieron la bandera independentista. Juan Camilo Rodríguez Gómez, "La Independencia del Socorro en la génesis de la emancipación colombiana”, Credencial Historia 242 (2010): 6.
} 
de estos territorios. Ese impulso se mantuvo firme al momento de empuñar las armas y, prueba de ello, es la trayectoria del batallón Socorro, ${ }^{5}$ convocado en 1813 por el general Antonio Nariño para luchar por la liberación del Sur de la Nueva Granada.

Cabe precisar que muy poca atención ha merecido el análisis exhaustivo de la estructura operativa de los ejércitos, ya sea a través de columnas, compañías o batallones pues la historia militar alusiva a las guerras de Independencia de Colombia se ha concentrado fundamentalmente en el estudio de las campañas y de las batallas más memorables, así como también en el gesto heroico de algunos militares. Desde la década de los sesenta del siglo XX, después de las dos guerras mundiales, adquirió auge la denominada nueva historia militar en un intento por abordar una mayor amplitud de temas, metodologías, fuentes e interacción con otras disciplinas. ${ }^{6}$ Teniendo como pioneras las historiografías británica, francesa y americana, la renovada historia militar ha abordado los ejércitos de una manera más integral, no solo desde el ámbito de la guerra sino articulado al estudio de la sociedad, la economía, la política y la cultura. ${ }^{7}$

En Colombia no existen trabajos académicos sólidos sobre la trayectoria de los batallones formados durante las guerras de Independencia, aunque han sido publicados algunos estudios sobre el periodo republicano, relativos unos a las guerras civiles y otros a la participación militar en conflictos externos. ${ }^{8}$ Desde el punto de vista historiográfico, el estudio de un batallón tiene la ventaja de que no se fija en un momento, sino que permite tener una visión más integral del fenómeno de la guerra en la medida en que propicia el análisis de la actividad militar como un proceso con todos sus matices, sus logros, sus desventuras y sus formas de superar las adversidades. Permite además adentrarnos en el funcionamiento y en las diferentes facetas de la composición de estos cuerpos, ya sea en su dimensión social, económica y política.

En el marco de la conmemoración del Bicentenario de la Independencia de Colombia, este artículo intenta profundizar sobre los logros y desventuras experimentadas por el batallón Socorro que desarrolló sus operaciones entre 1813 y 1816 en la campaña dirigida a expulsar los españoles de las provincias del sur de la Nueva Granada y en la defensa del epicentro del poder republicano. Este cuerpo, de origen provincial, emprendió su accionar en medio de un ambiente de polarización

\footnotetext{
${ }^{5}$ En algunos documentos este mismo cuerpo aparece como Cazadores del Socorro.

${ }^{6}$ Cristina Borreguero Beltrán, "La historia militar en el contexto de las nuevas corrientes historiográficas. Una aproximación”, Manuscrits. Revista d'História Moderna 34 (2016): 150.

${ }^{7}$ María Dolores Herrero Fernández-Quesada, "La investigación en historia militar de la Edad Moderna y sus fuentes", Cuadernos de Historia Moderna 38 (2013): 168-171.

${ }^{8}$ Entre estos trabajos cabe mencionar: Enrique Naranjo Martínez, "El batallón Pichincha", Boletín de Historia y Antigüedades 230 (1933): 262-265; Otoniel Arango Collazos, Batallón de Artillería No. 8 Batalla de San Mateo (Bogotá: Escuela Militar José María Córdova, 2013); Alberto Ruíz Novoa, El batallón Colombia en Corea (Bogotá: Empresa Nacional de Publicaciones, 1956). En cuanto al contexto hispanoamericano sobresalen algunos trabajos realizados en México. Véase, por ejemplo: Isidro Alemán, Apuntes para la historia del batallón Matamoros de Morelia, (Morelia: Universidad Michoacana, 1997); Patricia Cox, Batallón de San Patricio (México D.F.: San Jerónimo Editores, 1999); Miguel Domínguez Loyo, El batallón expedicionario de Asturias y su comandante don Juan de Cándano: episodios de la guerra de Independencia (México D.F.: Editorial Citlaltepetl, 1964).
} 
política interna y, a pesar de todas las vicisitudes de la guerra, sirvió de base para el paso de fuerzas milicianas a veteranas, aspecto que sería clave dentro del proceso de formalización y profesionalización de las tropas republicanas con las cuales fue posible años después culminar la liberación del territorio neogranadino.

La trayectoria misma de este batallón (Ver mapa No. 1) reflejó en cierto modo los avances y retrocesos de la Campaña del Sur. Primero una ofensiva y consolidación de sus fuerzas en la marcha desde Santa Fe con un balance positivo en los combates sostenidos, aunque la derrota en Pasto marcaría un punto de inflexión que lo obligó a replegarse. Si bien el batallón logró recuperarse durante su estadía en Popayán y en el Valle del Cauca, al final se debilitó por cuenta de las vacilaciones de los altos mandos militares, la persistencia de las fricciones políticas internas y principalmente por la enorme amenaza que significaba la llegada del ejército español de Reconquista.

Esta investigación se realizó principalmente con base en fuentes primarias de información, en especial con fondos de archivos documentales, sumado al intercambio epistolar entre autoridades políticas y militares, los informes oficiales, las memorias, las crónicas, los diarios de campaña y los artículos de prensa de la época. Todo esto complementado con la revisión de artículos y libros alusivos a la temática objeto de estudio.

\section{La Campaña del Sur y los orígenes del batallón}

Luego de 1810, tras el advenimiento de las primeras manifestaciones de autonomía política en la Nueva Granada, empezó a diluirse la lealtad monárquica de las fuerzas militares existentes y adquirió más fuerza el apoyo de estas tropas a las recién conformadas juntas locales de gobierno, allanándose de esta forma el camino para el fortalecimiento de las intenciones emancipatorias. ${ }^{9}$

Si bien las autoridades españolas lograron la ventaja de contar en un principio con ejércitos formados y disciplinados, los líderes del gobierno independiente iniciaron un proceso de reclutamiento siguiendo el modelo de unidades de milicia en el cual tuvieron cabida sectores de la sociedad de diferente condición social y étnica, ${ }^{10}$ vinculados ya fuera de manera voluntaria o mediante el método de la fuerza y la intimidación. Ante la falta de pagos y de conocimientos teóricos militares, en estos grupos de milicianos adquirieron relevancia en el campo de batalla algunas habilidades y motivaciones altruistas, con actitudes desafiantes y con tintes de heroísmo. ${ }^{11}$

\footnotetext{
${ }^{9}$ Allan J. Kuethe, Reforma militar y sociedad en la Nueva Granada, 1773-1808 (Santafé de Bogotá: Banco de la República, 1993) 377.

${ }^{10}$ Clément Thibaud, Repúblicas en armas. Los ejércitos bolivarianos en la guerra de Independencia en Colombia y Venezuela (Bogotá: Planeta-Ifea, 2003) 207.

${ }^{11}$ Jairo Emilio Mejía Argüello, "Arquetipos y paradigmas históricos en los militares colombianos. Exploración desde la Conquista al siglo XXI", De milicias reales a militares contrainsurgentes. La institución militar en Colombia del siglo XVIII al XXI, César Torres del Río y Saúl Rodríguez Hernández (Bogotá: Editorial Pontificia Universidad Javeriana, 2008) 106. Véase las descripciones que sobre estas virtudes heroicas hicieron en su momento: Luis Perú de la Croix, Diario de Bucaramanga (Cali: Fundación para la Investigación y la Cultura, 1999) 80-81; José María Samper, Ensayo sobre las revoluciones políticas
} 
Para la defensa común del territorio, el Congreso de las Provincias Unidas dispuso que debían formarse ejércitos, para lo cual había que asignar a cada provincia el número de milicias acorde a su población y recursos debiendo dotarlas y equiparlas adecuadamente. ${ }^{12}$ Tal como señala el historiador Clément Thibaud, la guerra que se vivió durante estos años en contra los españoles fue de baja intensidad y más que todo defensiva, con una serie de combates parciales que no hacían posible el aniquilamiento total del enemigo debido a lo reducido de las tropas, la falta de organización militar, las dificultades geográficas y la fuerte influencia ejercida por la opinión política de los pueblos. ${ }^{13}$

La lucha interna entre centralistas y federalistas había sido intensa y marcada por disputas políticas entre facciones locales y con algunos combates que no arrojaron un vencedor absoluto. Si bien en 1813 había amainado este conflicto, el brigadier español Juan Sámano y el capitán general de Quito don Toribio Montes seguían desafiantes en las provincias de Popayán y Pasto. Luego de fracasar en su intento por apoderarse del Socorro tras la traición de sus oficiales Antonio Baraya y Joaquín Ricaurte, el debilitado presidente de Cundinamarca don Antonio Nariño propuso un cambio radical de planes que consistía en desistir de su proyecto político de atacar militarmente a los federalistas de la ciudad de Vélez defendidos por el general Gregorio Mac Gregor y en lugar de ello salir al frente de una expedición en auxilio de Popayán, siempre y cuando marcharan con él las tropas de la Unión, especialmente aquellas ubicadas en la villa del Socorro, reconocido fortín federalista.

Mediante decreto dictado el 26 de mayo de este año y, bajo un espíritu conciliador, el Congreso de las Provincias Unidas decidió nombrar a Nariño como Comandante Supremo del Ejército y aceptó su ofrecimiento de emprender esta campaña con miras a la "salvación de la Nueva Granada". El inmenso reto en medio de la estrechez económica era reunir los 300.000 pesos del empréstito solicitado por este general, para lo cual se pidió acudir a la solidaridad de las provincias de Antioquia, Chocó y Neiva. ${ }^{14}$ El 30 de mayo los representantes de Cundinamarca y de las Provincias Unidas firmaron el fin de la guerra interna y formalizaron su intención de independizarse de España y aglutinar sus fuerzas para expulsar los reductos de resistencia realista en el Sur en momentos en que Simón Bolívar emprendía la Campaña Admirable que le permitiría liberar el occidente y centro de Venezuela y fundar allí la Segunda República.

El máximo órgano legislativo le otorgó plenos poderes a Nariño para la organización del ejército y el nombramiento del cuadro de oficiales. Así entonces, se impartieron instrucciones al comandante y tropas existentes en El Socorro para que se pusieran bajo el mando de Nariño, ordenándose además proveerlos con las

\footnotetext{
(Bogotá: Universidad Nacional de Colombia, 1969) 189.

${ }^{12}$ Congreso de las Provincias Unidas (Bogotá: Biblioteca de la Presidencia de la República, 1989), tomo I, 4-5.

13 Thibaud 156.

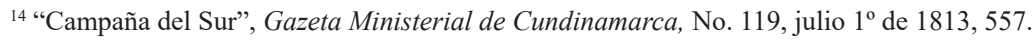


armas necesarias para la misión encomendada ${ }^{15}$ y a los pueblos de tránsito se les pidió colaboración para el sostenimiento de estas huestes en su marcha. ${ }^{16}$

Mapa No. 1:Ruta recorrida por el batallón Socorro en la Nueva Granada entre junio de 1813 y julio de 1816

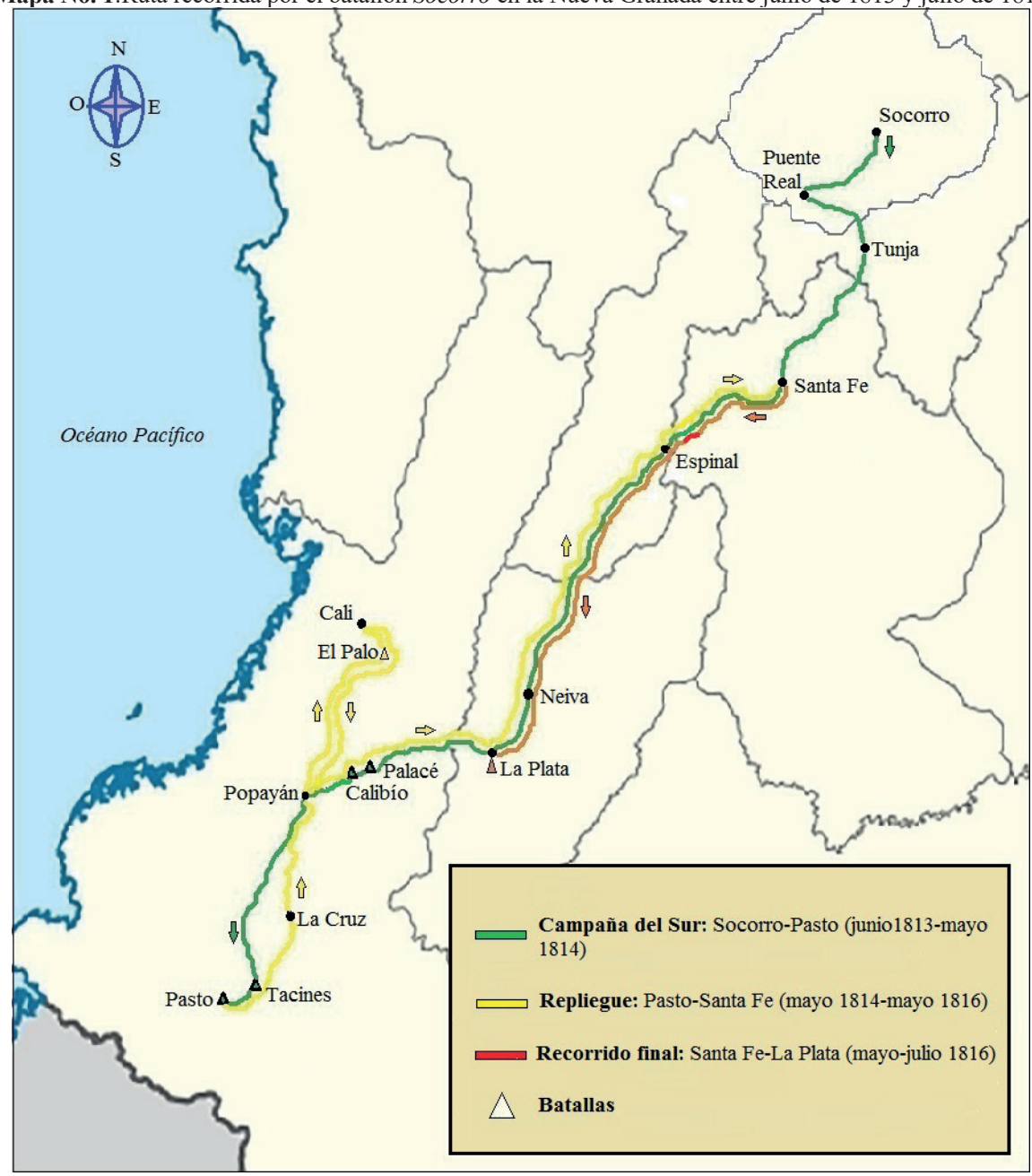

Fuente: mapa elaborado por el autor con base en las fuentes documentales aquí reseñadas.

El ambiente de polarización política interna aún estaba latente y no dejaron de suscitarse ciertas desconfianzas. Tal fue el caso del gobernador del Socorro don Custodio García Rovira quien sospechaba que la verdadera intención de Nariño era regresar triunfante "como Bonaparte" y fortalecido de su campaña por el Sur para después asestar un golpe a la federación. Por su parte, el dirigente federalista Camilo Torres estaba a la expectativa de la buena fe de Nariño y solo así justificaba destinar el

\footnotetext{
${ }^{15}$ Eduardo Posada (Comp.), Congreso de las Provincias Unidas (Bogotá: Imprenta Nacional, 1924) 68-69.

${ }^{16}$ Gazeta Ministerial de Cundinamarca, No. 120, julio 7 de 1813, 561.
} 
batallón del Socorro a la "causa común" de expulsar a los españoles. Torres afincaba su esperanza en que estas bisoñas tropas adquirieran experiencia en esta campaña y se transformaran en veteranos que sabrían defender el espíritu militar y la libertad de su propia provincia. ${ }^{17}$

El Socorro, pese a ser una de las provincias más pobladas y prósperas desde finales del dominio hispánico, no concentró cuerpos militares de defensa como los que había en otras localidades de la Nueva Granada como Santa Fe, Popayán, Cartagena y Santa Marta. ${ }^{18}$ Después de la revuelta de los Comuneros que tuvo como epicentro aquella villa del nororiente neogranadino, para las autoridades virreinales fue una prioridad el refuerzo de los efectivos militares para evitar que se repitiera un hecho conspirativo de esta naturaleza. ${ }^{19}$ Con la llegada del periodo de Independencia, en esta provincia los dirigentes de orientación federalista ya habían realizado algunos reclutamientos en el marco de la confrontación política y militar con los centralistas ${ }^{20}$ aunque hay que reconocer que fueron muy escasos los esfuerzos del Congreso de las Provincias Unidas por formar allí unidades profesionales y veteranas de defensa que dieran vida a un ejército permanente. ${ }^{21}$

En momentos en que la expedición del Sur iniciaba su marcha, un hecho trascendental tuvo lugar el 16 de julio tras la declaratoria por parte del Colegio Electoral de Cundinamarca del "[...] total desconocimiento y separación absoluta de la Nación española y de su Rey Fernando VII", ${ }^{22}$ lo cual se constituyó en un estímulo para la campaña en ciernes. En desarrollo de este proyecto militar al mando del general Nariño, el gobernador del Socorro don Custodio García Rovira informó cómo las tropas de aquella provincia que debían reforzar la expedición partieron de la población de Puente Real el día 30 de julio, trayendo 22 cargas de arroz, 3.000 cartuchos, 2.000 balas y 8.000 pesos para sus pagas. Estos fueron los términos en que el funcionario provincial reiteró su más firme intención de apoyo:

\footnotetext{
${ }^{17}$ Antonio Cacua Prada, Custodio García Rovira: el estudiante mártir (Bogotá: Academia Colombiana de Historia, 1983) 67-71.

${ }^{18}$ José Semprún y Alfonso Bullón de Mendoza, El ejército realista en la Independencia americana (Madrid: Editorial Mapfre, 1992), 93; Germán Colmenares (Comp.), Relaciones e Informes de los Gobernantes de la Nueva Granada (Bogotá: Biblioteca Banco Popular, 1989), tomo III, 249.

${ }^{19}$ Álvaro Valencia Tovar, "La Colonia”, Historia de las Fuerzas Militares de Colombia (Bogotá: Editorial Planeta, 1993), tomo I, 53.

${ }^{20}$ Uno de estos reclutamientos se llevó a cabo a finales de 1814 cuando se lograron incorporar 400 hombres de los Bravos del Socorro para sumarse a las fuerzas convocadas en el Congreso de Tunja para atacar la ciudad de Santa Fe. Algunos de estos hombres quedaron de guarnición de esta capital y otros salieron de esta capital en enero del año siguiente dentro de la frustrada campaña de liberación de Santa Marta. "Noticias interiores", Gazeta Ministerial de Cundinamarca, No. 208, febrero 2 de 1815, 1.020; Simón O'Leary, Memorias del General O'Leary (Caracas: Imprenta de la Gaceta Oficial, 1983), tomo XIII, 570581. Otra leva se realizó en 1815 con miras a la creación del batallón del Socorro que uniría sus fuerzas al Ejército del Norte que fue derrotado el 22 de febrero de 1816 en la batalla de Cachirí. Camilo Riaño, $L a$ batalla de Cachirí, (Bogotá: Imprenta y Publicaciones de las Fuerzas Militares, 1966) 22; Pérez 82.

21 Thibaud 162.

${ }^{22}$ Pedro M. Ibáñez, Crónicas de Bogotá, (Bogotá: Biblioteca Popular de Cultura Colombiana, 1951), tomo III, 78.
} 
Hasta ahora me ha merecido la mayor confianza esta gente y principalmente los oficiales. Ojalá que su conducta los haga acreedores a la de vuestra excelencia. Queda este gobierno con responsabilidad a mandar cuantas cantidades sean necesarias para sostener su tropa en todo el tiempo que dure la expedición [...] Aún podrá salir mucha más gente de esta provincia, siempre que la satisfacción de los sueldos no se haga de su erario, y si se da algún tiempo para alistarla, y ponerla en estado de marchar. Si vuestra excelencia cree que se necesita más de la que va, sírvase decirme hasta qué número, y a qué punto la debo dirigir. En general, vuestra excelencia puede estar en la firme confianza de que cualquier clase de auxilios que se puedan sacar de esta provincia contra los enemigos comunes los franqueará su gobierno inmediatamente con el aviso oportuno. ${ }^{23}$

El batallón de infantería de El Socorro hacía alusión a su origen provincial como una clara influencia de la tendencia federalista imperante en este territorio. Específicamente, en sus inicios surgió como una compañía de milicianos que se convirtieron en fusileros en proceso de aprendizaje y que con el paso del tiempo se constituyeron en cuerpos de reserva para batallones de combate más experimentados. ${ }^{24}$

En términos generales, este cuerpo se inscribía dentro de la categorización trazada por el historiador Clement Thibaud respecto de las huestes neogranadinas que emprendieron las campañas militares para expulsar del norte y del sur a los españoles. Según Thibaud, esta compleja formación de tropas en medio de soberanías provinciales emergentes y luchas políticas internas, se caracterizaron por la permeabilidad, la falta de tradición militar y el ascenso vertiginoso de los cuadros de oficiales a medida que se sumaban más combates. La primera de estas características hacía alusión a la mezcla de soldados de distintas regiones de acuerdo a las vicisitudes y contingencias de la guerra. ${ }^{25}$

El viernes 6 de agosto el cronista José María Caballero reportó la llegada a Santa Fe de los primeros 200 hombres armados provenientes del Socorro, bajo la orientación del capitán Pedro Monsalve, ${ }^{26}$ en momentos en que aumentaba el estado de alarma al saberse de la toma de Popayán por parte del brigadier español Juan Sámano. A la semana siguiente, se hallaba este cuerpo efectuando ejercicios militares en la plaza central de Santa Fe y mostrando notorios avances gracias al arduo entrenamiento a que eran sometidos en las mañanas y en las tardes. El domingo 15 de agosto nuevamente se les vio en prácticas y esta vez "[...] ya uniformados, de manta, gorra y escarapela de independencia y el Jesús". ${ }^{27}$ Por la tarde del día

\footnotetext{
${ }^{23}$ Guillermo Hernández de Alba, (Comp.), Archivo Nariño (Bogotá: Biblioteca de la Presidencia de la República, 1990), tomo V, 167-168.

24 Thibaud 166.

25 Thibaud 161-162.

${ }^{26}$ Este oficial, nacido en El Socorro, se enroló en las fuerzas independientes que alzaron su voz de protesta en esta villa el 10 de julio de 1810 y en Santa Fe el 20 de julio. Al lado de los centralistas, participó en la batalla de Ventaquemada contra las fuerzas federalistas al mando del oficial Antonio Baraya. Leonidas Scarpetta y Saturnino Vergara, Diccionario biográfico de los campeones de la libertad de Nueva Granada, Venezuela, Ecuador i Perú (Bogotá: Imprenta de Zalamea, 1879) 339-340.

${ }^{27}$ En este caso se registró un cambio de protector espiritual pues los federalistas tenían como patrona la
} 
siguiente emprendieron la larga travesía hacia Popayán "con mucho lucimiento y uniformidad". ${ }^{28}$ Según otro de los cronistas de la época, el abanderado José María Espinosa, el batallón estaba conformado no solo por socorranos sino además con otros oriundos de Pamplona, Cúcuta y Vélez. ${ }^{29}$ Es muy probable que se hayan integrado también algunos emigrados venezolanos que huían de la persecución y de la crueldad de los españoles. ${ }^{30}$ Junto a este cuerpo partieron también los batallones Granaderos de Cundinamarca, Guardias Nacionales, Patriotas y Tunja. Además, se contó con el refuerzo de tropas organizadas en Antioquia e Ibagué que de manera simultánea avanzaban por el Valle del Cauca. ${ }^{31}$

El 23 de octubre llegó a la capital otra tropa proveniente del Socorro con el brigadier inglés Mac-Gregor como comandante. En total, eran 200 hombres que venían sin armas. Al cabo de cinco días, salió este nuevo contingente para unirse a los demás y se programó que debían tomar las armas en la villa de Purificación o en Neiva porque en Santa Fe todavía se desconfiaba de estos militares provenientes de un bastión federalista. ${ }^{32}$ No obstante, al final el oficial inglés fue llamado a unirse a las fuerzas del general Custodio García Rovira en sus operaciones en la región nororiental. Para ese momento, el total de las fuerzas del ejército republicano era de 1.200 hombres de infantería y aproximadamente 200 de caballería.

\section{La Campaña del Sur: fase ofensiva}

En su marcha hacia el Sur, el general Nariño y su ejército avanzaron por el habitual camino de la provincia de Neiva. El 26 de octubre de 1813 el batallón Socorro se hallaba en la villa del Espinal y allí se pidió a sus habitantes un donativo de 3.000 para el sostenimiento de la tropa. ${ }^{33}$ A los pocos días se ubicó en cercanías de La Plata y estando allí comenzaron los hostigamientos de los realistas y de sus espías ${ }^{34}$ en momentos en que Nariño había dictado algunas normas concernientes a la disciplina militar, una de ellas ampliando el indulto a los desertores y la otra reglamentando el Consejo de Guerra Permanente. ${ }^{35}$

\footnotetext{
Virgen del Socorro y ahora adoptaban a Jesucristo como protector de los centralistas. Cacua, Custodio García 62.

${ }^{28}$ José María Caballero, Particularidades de Santafé (Bogotá: Academia Colombiana de Historia, 1989) 176-178.

${ }^{29}$ José María Espinosa, Memorias de un abanderado (Bogotá: Banco Popular, 1971) 57.

${ }^{30}$ Esta hipótesis se deduce de los comentarios hechos por el político socorrano Florentino González en sus memorias. Florentino González, Memorias (Medellín: Editorial Bedout) 43-44.

${ }^{31}$ Rafael Negret, Campaña del Sur del General Don Antonio Nariño, 1813-1814 (Bogotá: Imprenta del Estado Mayor General, 1919) 14.

${ }^{32}$ Diego Castrillón Arboleda, Manuel José Castrillón. Biografia y Memorias (Bogotá: Banco Popular, 1971), tomo I, 118-119.

${ }^{33}$ Horacio Rodríguez Plata, La antigua provincia del Socorro y la Independencia (Bogotá: Academia Colombiana de Historia, 1963) 277.

34 “Autobiografía de Antonio Obando", Boletín de Historia y Antigüedades, VIII. 93 (1913): 532.

35 "Noticias", Gazeta Ministerial de Cundinamarca, No. 149, diciembre 23 de 1813, 678-679.
} 
El 19 de diciembre dos socorranos atentaron contra la vida del general Nariño, lo cual se atribuyó a viejas rencillas políticas internas y al ánimo de vengar la derrota que sufrieron los centralistas en la batalla de Santa Fe ocurrida el 9 de enero de $1813 .{ }^{36}$ Luego de reorganizar el ejército y de adelantar los preparativos de viaje, la tropa salió el 22 de diciembre y se dispuso a atravesar la cordillera Central por el tradicional camino de Guanacas ${ }^{37}$ y descendió al altiplano de Popayán mientras que el resto de las fuerzas republicanas optaron por seguir el camino del Quindío para después juntarse nuevamente. ${ }^{38}$

El 30 de diciembre se llevó a cabo el primer enfrentamiento militar en esta campaña. Las tropas llegaron a un alto cercano al río Palacé en donde 700 realistas al mando del brigadier Juan Sámano fueron vencidos. Nariño y su ejército entraron victoriosos a la ciudad de Popayán el último día de este año. A los pocos días se movilizaron hasta Calibío en donde el 15 de enero de 1814 los independentistas obtuvieron una nueva victoria. ${ }^{39}$ Monsalve al mando de la infantería del Socorro atacaron por el flanco izquierdo en medio de rastrojos y cañadas. Este fue su parte de batalla:

El enemigo rompió primero el fuego que duró por su parte tres horas, y observando yo que la artillería enemiga que era perfectamente servida nos quitaba algunos hombres, determinó acometer a bayoneta calada, cuyo ejemplo seguido por los demás aterró de tal suerte al enemigo que lo desordenó enteramente y lo puso en una precipitada fuga, dejando en el campo dos culebrinas, cuatro violentos y un cañón de a dos, muchísimos pertrechos. ${ }^{40}$

En el bando realista perecieron más de 360 hombres y 80 más cayeron prisioneros. ${ }^{41}$ En el lado patriota, Monsalve reportó 14 bajas, de las cuales 4 pertenecían a su batallón. El número de heridos se elevó a 34, siendo 8 de ellos del cuerpo de socorranos. Estos 12 soldados del batallón Socorro hacían parte del grupo que aquel oficial había incorporado en la parroquia de Puente Real. Fue elogiado el valor de los capitanes Vicente Vanegas y Vicente Acevedo, y se resaltó también la participación del sargento segundo Jesús Padilla y del cabo primero Cayetano Vásquez. ${ }^{42}$ Después de este triunfo, el 17 de marzo el comandante José María Cabal marchó con 500 hombres, 100 de ellos del batallón Socorro, hasta el pueblo del Tambo. En el mes de abril este cuerpo estaba compuesto por 215 efectivos. $^{43}$

\footnotetext{
${ }^{36}$ Caballero 187-190.

${ }^{37}$ Camilo Riaño, "La Independencia (1810-1815)", Historia Extensa de Colombia, Vol. XVIII [Historia Militar], tomo 1 (Bogotá: Ediciones Lerner, 1971) 335.

${ }^{38}$ Espinosa 50.

${ }^{39}$ Batalla de Calibio (Popayán: Ejército Nacional, 1975), 10; Alberto Andrade, José María Cabal. Prócer de la Independencia (Bogotá: Imprenta de las Fuerzas Militares, 1973) 55.

${ }^{40}$ Argos de la Nueva Granada, No. 17, marzo 3 de 1814, 69.

${ }^{41}$ Archivo General de la Nación (AGN), Sección Archivo Anexo, Fondo Historia, tomo 15, ff. 545r-546r.

${ }^{42}$ Hernández, tomo IV, 325.

${ }^{43}$ Hernández, tomo V, 299.
} 
Alentados por estas dos victorias sucesivas, las tropas patriotas se enfrentaron al temible paso del Juanambú y a la guerrilla de los patianos de reconocida lealtad al Rey, que se convirtieron en el símbolo de la resistencia realista y en el tormento para el ejército republicano que operaba en el Sur. Nariño envió los hombres del batallón Socorro para que de manera muy cautelosa sorprendieran por la retaguardia a los enemigos. Finalmente, Pedro Monsalve, quien hacía poco había sido ascendido a teniente coronel $^{44}$ por sus méritos, lideró la operación. Al final, solo 40 hombres al mando del alférez Juan José Vanegas, oriundo de Vélez, pudieron cruzar el río Juanambú gracias a la ayuda de una improvisada tarabita ${ }^{45}$ para después coronar la cima. Según los relatos, para esta misión "[...] era necesario trepar riscos muy escarpados, haciendo escalas con las bayonetas y corriendo graves peligros de precipitarse". ${ }^{46}$ Esta fue, sin duda, la operación más resaltada por testigos y cronistas en esta Campaña del Sur.

Intempestivamente, Vanegas y sus más de 40 hombres fueron descubiertos

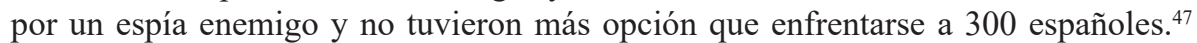
La primera embestida fue de tal magnitud que obligó a los realistas a abandonar sus posiciones, pero estos se percataron rápidamente del reducido número de hombres que los atacaban. La crecida del río había impedido respaldar a Vanegas en su operación, de la cual únicamente se salvó este jefe militar y 10 de sus soldados que pudieron guarecerse improvisadamente en los huecos de aquellos riscos rocosos.

Aunque fue frustrado este primer intento de los patriotas por franquear el paso por el Juanambú, al final permitiría reorientar el ataque y superar este complicado tramo de la marcha. Por su arriesgada misión, Vanegas fue ascendido al grado de teniente y Monsalve a coronel mientras que Nariño decretó un premio de valor a los soldados sobrevivientes. ${ }^{48}$ En la acción resultaron en total 37 patriotas aniquilados, algunos prisioneros, otros ahogados y otros arrojados desesperadamente por el precipicio. ${ }^{49}$

Al tercer día el Ejército del Sur llegó al pie del cerro Tacines en donde estaba cerca el ejército español y, tras una junta de generales, se decidió dar la batalla en este sitio. Los republicanos contabilizaron en sus filas un total de 300 víctimas, entre las cuales estaba Vanegas, el destacado alférez en Juanambú. Entre tanto, fueron muy pocas las bajas del lado español, gracias a que estuvieron mejor resguardados en la cima.

\footnotetext{
${ }^{44}$ Hernández, tomo V, 325.

${ }^{45}$ Cuerda gruesa por medio de la cual se desplaza una silla utilizada para transportar personas o carga a través de un río.

${ }^{46}$ López, tomo I, 47-48.

${ }^{47}$ Alejandro Osorio, “Campaña de Nariño en el Sur”, Boletín de Historia y Antigüedades 96 (1913): 739740; Camilo Riaño, La batalla del Juanambú (Bogotá: Imprenta Fuerzas Militares, 1965) 10.

${ }^{48}$ Hernández, tomo V, 330.

${ }^{49}$ Luis Ervin Prado Arellano y David Fernando Prado Valencia, Laureano López y Joaquín Mosquera. Recuerdos de dos payaneses sobre la guerra de Independencia y la disolución de Colombia (Bucaramanga: Universidad Industrial de Santander, 2012) 49-50.
} 
En momentos en que se aprestaba a atacar la ciudad de Pasto, que era el máximo bastión monárquico al sur de la Nueva Granada, Nariño impartió órdenes al capitán Acevedo del batallón Socorro, acreditado por su valor, para que tomase 40 hombres de su compañía y marchara a la avanzada. Al manifestar Acevedo que aún no estaba listo, la impaciencia se apoderó de Nariño y mandó a Monsalve para que iniciara el ataque. Este oficial junto con 60 de sus hombres escoltó a su superior y así se emprendió la marcha de toda la división. A comienzos del mes de mayo, el Ejército del Sur con una fuerza menguada que se aproximaba a los 800 hombres llegó a los ejidos de Pasto sin haber encontrado al comienzo mayor resistencia, observándose cómo muchas gentes y soldados huían por el camino de Quito. Ya en los combates, Monsalve y sus hombres se vieron precisados a luchar cuerpo a cuerpo con el uso de armas blancas, pero al verse rodeados se dio orden de retirada debiendo soportar el acoso de los realistas que los superaban en pie de fuerza. ${ }^{50}$

Finalmente, el 11 de mayo Nariño lanzó la gran ofensiva, pero la falta de artillería y de municiones le impidió obtener el triunfo. Este comandante no contó con el pleno refuerzo de su ejército pues se difundió la falsa noticia de que había sido tomado como prisionero ante lo cual las desmoralizadas fuerzas acantonadas en Tacines decidieron inutilizar la artillería y emprender la retirada. Existió en este momento crucial mucha confusión y falta de liderazgo para dirigir las huestes republicanas. ${ }^{51}$

Al final, Nariño fue capturado cuando huía y fue enviado preso a España, derrota que le causó un gran costo político con el que debió lidiar hasta el fin de sus días. ${ }^{52}$ Este fue el mayor golpe para el Ejército del Sur y marcó el inicio del declive de sus fuerzas. Notorio fue también el efecto de estos sucesos en la frágil unidad política entre centralistas y federalistas, lo que a su vez alentaría a los españoles a intensificar su ofensiva. ${ }^{53}$ Infortunadamente para los intereses patriotas, esta derrota coincidió con los hechos en España que permitieron la expulsión de los franceses y el retorno de Fernando VII al trono, quien de inmediato propuso como uno de sus principales objetivos la restitución del Absolutismo, la derogación de la Constitución de Cádiz y la reintegración del imperio español, lo cual implicaba la organización de una gran estrategia militar para recuperar los territorios americanos sublevados.

\footnotetext{
${ }^{50}$ López, tomo I, 59-61.

${ }^{51}$ Antonio Cacua Prada, Yo soy Nariño (Bogotá: Editora Guadalupe, 2008) 243-244.

${ }_{52}$ Melchor Aymerich, Diario de Operaciones del Exército Real (Lima: Imprenta de los huérfanos por D. Bernardino Ruíz, 1814), 19; Sergio Elías Ortiz, Colección de documentos para la historia de Colombia. (Época de la Independencia) (Bogotá: Academia Colombiana de Historia, 1964) Primera Serie, 54-72.

${ }^{53}$ Jorge Conde Calderón, "Las pugnas entre centralistas y federalistas", en: Historia de la Independencia de Colombia. Revolución, Independencias y guerras civiles (Bogotá: Presidencia de la República, 2010), tomo I, 92.
} 


\section{Repliegue y viaje hacia Santa Fe}

Tras las pérdidas sufridas en el ataque a Pasto y la prisión del general Nariño, los restos de los batallones Granaderos y Socorro retrocedieron a Popayán para reorganizar el ejército, acopiar provisiones, pedir recursos a Santa Fe y planear nuevas operaciones. ${ }^{54}$ Se colocó en la retaguardia una compañía de cazadores del batallón Socorro a órdenes del capitán Vicente Acevedo. ${ }^{55}$

En ese camino de retorno, las fuerzas patriotas fueron atacadas incesantemente por los guerrillas realistas del Patía luego de pasar el río Mayo cerca del pueblo de La Cruz y atravesar los pueblos de El Trapiche ${ }^{56}$ y La Sierra. El general Cabal, quien tras la ausencia de Nariño había asumido como comandante en jefe del ejército, impartió instrucciones a Monsalve para que se camuflara en las alturas con una partida de 100 hombres y, al descender los patianos sobre el resto del ejército independiente, le saliera a su retaguardia y los atacara velozmente. El plan se ejecutó como estaba previsto, pero fueron muy pocos los realistas que murieron pues muchos lograron escaparse "como liebres por los riscos, aunque bastante escarmentados". Fueron en total 17 penosos días hasta que finalmente los patriotas llegaron a Popayán en donde pudieron permanecer por algunos meses hasta finales de 1814. Allí lograron reponerse de los combates anteriores, registrándose algunas deserciones en la tropa.

Mientras esto acontecía en el Sur, las tensiones políticas internas subieron de tono. Las Provincias Unidas decidieron entregar el mando militar a Simón Bolívar, quien había buscado refugio en la Nueva Granada al huir de Venezuela tras el avance español y el derrumbe de la Segunda República. Este oficial marchó hacia el interior y tomó el control armado de la ciudad de Santa Fe el 12 de diciembre de 1814, ${ }^{57}$ con lo cual Cundinamarca quedó incorporada a la federación.

Ante la falta de auxilios y alimentos en Popayán, ciudad que se había mostrado indecisa frente a la causa patriota, los altos oficiales del Ejército del Sur dispusieron el traslado al Valle del Cauca para aliviar las necesidades y aumentar el pie de fuerza con miras a resistir al enemigo que se preparaba en Pasto para lanzar una ofensiva sobre Popayán, objetivo final que sin muchos obstáculos pudo concretarse a principios de 1815 .

Habiendo llegado las vapuleadas tropas patriotas a Cali, se recibieron noticias ciertas de que estaba por llegar un ejército de 1.500 españoles al mando del general Aparicio Vidaurrázaga. Así entonces, el general Cabal aunó esfuerzos para conformar un ejército entrenado ${ }^{58}$ y ordenó que el batallón Socorro se ubicara "como descubierta" en el camino de Quilichao con un destacamento en el río Ovejas, con el

\footnotetext{
${ }^{54}$ Espinosa 85.

${ }^{55}$ Prado y Prado 59.

${ }^{56}$ Hoy municipio de Bolívar, departamento del Cauca.

57 "Relación de sucesos". Gazeta Ministerial de Cundinamarca, No. 204, enero 5 de 1815, 998-1.000.

${ }^{58}$ Thibaud 158.
} 
fin de entretener a las fuerzas de vanguardia enemiga mientras se tomaban posiciones y se organizaba la defensa. Por estos días el pie de fuerza del ejército republicano se había reducido a 700 hombres.

Al tercer día de estar cumpliendo los del Socorro con la misión encomendada, fueron atacados por una fuerza mayor, ${ }^{59}$ ante lo cual debió salir presurosamente a prestar ayuda el cuerpo de Granaderos de Cundinamarca. Cuando estos hombres se acercaban a Quilichao, vieron a los del Socorro en retirada y, tras reunir fuerzas, lograron correr momentáneamente a los realistas. Sin embargo, la actitud de los españoles de retirarse no era más que una estrategia para tender una trampa mayor a los patriotas que ya habían entrado al pueblo a las siete de la noche y se habían posicionado en la plaza. En efecto, a las pocas horas los españoles atacaron con más ímpetu y lograron recuperar el dominio sobre Quilichao debiendo los patriotas replegarse hacia Caloto. ${ }^{60}$ Cerca de allí, en el sitio llamado Pílamo, se ubicó una avanzada del batallón Socorro al mando del teniente Serrano. ${ }^{61}$

El 7 de marzo de 1815 se aprobó la formación del segundo batallón del Socorro, bautizado con el nombre Bravos del Socorro, el cual debía estar integrado por cinco compañías: una de granaderos, una de cazadores y tres de fusileros. ${ }^{62} \mathrm{Sin}$ embargo, este cuerpo nunca llegó a consolidarse. Según el parte dado el 27 de mayo en la población de Llanogrande, ${ }^{63}$ el Ejército del Sur contaba con las siguientes fuerzas: Artillería, Caballería, Cundinamarca, Socorro, Popayán, Antioquia y Cauca. En el siguiente cuadro aparecen descritas las fuerzas con que contaba el batallón Socorro:

Cuadro No. 1

\begin{tabular}{ll} 
Composición del batallón Socorro en mayo de \\
\hline Efectivos & No. \\
\hline Suboficiales & 40 \\
Tambores & 8 \\
Pitos & - \\
Soldados & 161 \\
Fusiles & 199 \\
Bayonetas & 144 \\
Fornituras & 165 \\
\hline
\end{tabular}

Fuente: Riaño, “La Independencia”, 569.

Este cuerpo solo era superado en número por el batallón Antioquia que contaba con 280 hombres. Por estos días, sin que todavía lo supieran las fuerzas republicanas que operaban en estas tierras del Sur, se asomaba por el puerto de

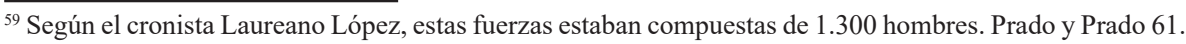

${ }^{60}$ Espinosa 99-100.

${ }^{61}$ Espinosa 105.

${ }^{62}$ Argos de la Nueva Granada, No. 71, abril 30 de 1815, 367.

${ }^{63}$ Hoy municipio de Palmira en el departamento del Valle del Cauca.
} 
Cartagena el ejército español de Reconquista al mando del general Pablo Morillo, con sus más de 10.000 hombres. Aunque con la reciente derrota de las fuerzas centralistas se habían despejado las disensiones políticas internas, ya era muy tarde para formar un sólido frente común de defensa en contra de las huestes invasoras.

Sin duda, en estos momentos de la campaña, la gran dificultad que experimentaba el vapuleado Ejército del Sur era su propensión a la deserción que se manifestaba desde el momento mismo en que comenzaban a instruirse en el manejo de las armas teniendo como pretexto la necesidad imperiosa de regresar con sus familias. Tal como lo denunciaba Cabal, con estas fugas recurrentes y la falta de sueldos era muy difícil pasar del plano defensivo al ofensivo y por ello la recomendación era completar con veteranos los batallones existentes, incluyendo el del Socorro y permitir que un buen número de milicianos retornaran a sus casas y a sus habituales labores agrícolas y productivas. Incluso pensaba que lo más aconsejable era que batallones como el $1^{\circ}$ de Santa Fe y el $2^{\circ}$ del Socorro resarcieran su pie de fuerza con hombres oriundos de sus respectivas provincias, tal como se había hecho hacía poco con el batallón Antioquia $^{64}$. Por estos días, era también una preocupación para Cabal la dificultad que tenía para desplegar su unidad de mando sobre el ejército, todo esto debido a la diversa composición regional y social de los batallones, observándose por ejemplo en el de Antioquia algunas decisiones autónomas y deliberadas. ${ }^{65}$

A mediados de junio el cuartel general del ejército republicano se había instalado a la margen izquierda del río Palo mientras que las huestes españolas se acercaban amenazantes desde Popayán. Los patriotas se vieron robustecidos con refuerzos procedentes de Neiva y Antioquia, registrándose además la llegada del coronel Manuel Serviez en calidad de jefe del Estado Mayor General. En total, se había logrado aglutinar un pie de fuerza de 1.300 hombres. Por estos días la comandancia del ejército republicano había solicitado a la Secretaría de Guerra autorización para adoptar el reglamento francés de Estados Mayores pues se consideraba más completo que las Ordenanzas militares españolas vigentes. ${ }^{66}$

A Monsalve se le pidió reunir su batallón y otros cuerpos más con el fin de situarse en las alturas de Ovejas como punto de observación. Sorpresivamente, los realistas se lanzaron al campo del Palo y Monsalve fue el primero en irse al ataque con el arrojo que lo caracterizaba y con un corto número de 400 hombres resistió a más de 2.000 realistas batiéndose luego en retirada hacia Quilichao, aunque después regresó al Palo a seguir hostigando al enemigo. ${ }^{67}$ Según el cronista Santiago Arroyo, en este enfrentamiento militar Monsalve perdió entre 25 y 30 hombres, pero su retirada fue "tan diestra y acertada que se reputó por una victoria". ${ }^{68}$ Se distinguieron en este

\footnotetext{
${ }^{64}$ Archivo Histórico Restrepo (AHR), Revolución de Popayán, Fondo I, Vol. 18, f. 340r.

${ }^{65}$ Archivo Histórico Restrepo (AHR), Revolución de Popayán, Fondo I, Vol. 18, f. 335r.

${ }^{66}$ Riaño, La batalla de Río Palo, (Bogotá: Academia Colombiana de Historia, 1960), 5.

${ }^{67}$ López, tomo I, 73-74.

${ }^{68}$ Santiago Arroyo, Apuntes históricos sobre la revolución de la Independencia de Popayán. Tomado de: Biblioteca Nacional de Colombia (BNC), Fondo Cuervo, tomo 1.377, pieza 12, 203.
} 
combate los hombres de Monsalve y el oficial Liborio Mejía al mando del batallón Antioquia. ${ }^{69}$ Fue clave este triunfo pues quedó liberado por un tiempo el territorio del Cauca. ${ }^{70}$ Las fuerzas patriotas contramarcharon $\mathrm{y}$, después de buscar algunas provisiones, continuaron hacia Popayán en donde se llevó a cabo la entrada victoriosa el día 7 de julio. ${ }^{71}$ Con la toma de esta ciudad, los republicanos consiguieron algunas ventajas y extendieron su dominio hasta los límites con el valle del Patía.

Entusiasmado con este reciente éxito militar, el gobierno de la Unión creía que el ejército patriota debía emprender una segunda ofensiva sobre Pasto pero el general Cabal desistió de esta idea al poner de presente las desafortunadas experiencias ya vividas y las reiteradas noticias sobre la llegada a Cartagena del ejército expedicionario español al mando de Pablo Morillo, circunstancia que le impedía al gobierno asentado en Santa Fe seguir enviando recursos al Sur, razón por la cual el peso del sostenimiento de las fuerzas corrió por cuenta del gobierno provincial. ${ }^{72}$ Las guerrillas del Patía aún eran una amenaza latente y se rumoraba una nueva arremetida planeada por el brigadier español Juan Sámano desde el Sur sobre la ciudad de Popayán. Ante este panorama incierto, finalmente el gobierno de la Unión ordenó el 6 de septiembre de 1815 suspender cualquier plan de marcha hacia Pasto y optó por levantar reservas en el Valle del Cauca y fundir los cuerpos en batallones de 500 hombres. Por estos días el batallón Socorro, a diferencia de los otros cuerpos, seguía manteniendo su pie de fuerza con un total de 215 hombres. ${ }^{73}$

Entre los cambios ordenados en la composición de los cuerpos, se decidió agregar los reductos del batallón Cazadores del Cauca al batallón Socorro. Por otro lado, el gobierno de la Unión envió desde Santa Fe 100 hombres para agregarlos al Bravos del Socorro. Luego se intentó fusionar los batallones Antioquia, Bravos del Socorro y Neiva que, al sumar sus integrantes no llegaban a 500, pero sus comandantes se negaron alegando representar el esfuerzo combativo de sus provincias, cuyo nombre servía de incentivo a sus soldados para proseguir en la lucha. Así, por ejemplo, el comandante del batallón Bravos del Socorro adujo haber sido creado como cuerpo veterano y tener completo su cuadro de oficiales, estando algunos de sus soldados repartidos cumpliendo comisiones en otros batallones. ${ }^{74}$

A principios de 1816, el panorama para los republicanos no era muy alentador. Mientras en Santa Fe se dictaba un nuevo pero tardío reglamento militar, ${ }^{75}$

\footnotetext{
${ }^{69}$ Manuel Mariano del Campo Larraondo, Rasgos poéticos que pueden servir de apuntamientos sobre la historia de nuestra revolución (Chía: Universidad de La Sabana, 2012) 262.

${ }^{70}$ Espinosa 113-114.

${ }^{71}$ Camilo Riaño, La batalla de Río Palo, 22.

${ }^{72}$ Archivo Central del Cauca (ACC), Sala Independencia, Militar I-2 Administración, signatura 368, ff. 1r-6v.

${ }^{73}$ Riaño, "La Independencia” 595.

${ }^{74}$ Riaño, La batalla de Río Palo 28.

${ }^{75}$ Reglamento u organización militar para la defensa y seguridad de las Provincias Unidas de la Nueva Granada (Santafé: Imprenta de C. B. Espinosa por N. Lora), 1-35. Tomado de: BNC, Fondo Pineda, tomo 687, pieza 1.
} 
las amenazas habían obligado al gobierno confederado a dividir las fuerzas del Ejército del Sur para atender nuevos frentes de defensa en Buenaventura, Chocó, el paso del Quindío, Antioquia, Neiva y Santa Fe. Las tropas de Reconquista ya habían sitiado a Cartagena e invadían rápidamente el territorio. El comandante español Morillo marchaba sobre Santa Fe, el coronel Francisco Warleta había impuesto su dominio en Antioquia y se dirigía hacia el Valle del Cauca mientras que el comandante Antonio Plá se había apoderado del Chocó y tenía como mira la ciudad de Popayán. Por los lados del nororiente, las fuerzas de Reconquista al mando del coronel Sebastián de la Calzada que avanzaban por esta zona demostraron su superioridad al imponerse sobre las tropas del general Custodio García Rovira el 22 de febrero en la batalla de Cachirí, ${ }^{76}$ lo cual significó la desaparición de buena parte del ejército patriota.

En la siguiente misiva que enviara el 20 de marzo desde Popayán el general Cabal a Camilo Torres, presidente del gobierno federal, se observa la crítica situación que padecían las menguadas fuerzas del Sur y los cambios evidentes en la procedencia regional de sus integrantes:

El batallón de Monsalve, que se llama del Socorro, apenas se compone de algunos individuos de aquella provincia, siendo la mayor parte hijos de ésta, porque los socorranos que lo componían ya no existen a causa de haber muerto muchos en las diferentes acciones que hemos tenido, y de haberse ido más de 100 hombres con las armas en tiempo del señor [Manuel Bernardo] Álvarez. Pero los que van son todos veteranos y gente de confianza. El otro batallón del Socorro, con el título de Bravos, fue imaginario desde que salió de Santafé, y se ha disminuido hasta reducirse al número de 50 hombres de 100 que llegaron aquí. Estos se hallan en las avanzadas y distribuidos en partidas de guerrillas, con el fin de alejarlos de la ciudad, para evitar los robos y quejas continuas que había de ellos, y no es posible hacerlos seguir en esta ocasión. Pero a falta de ellos, se han sacado de los cuerpos los socorranos que había en ellos y he procurado reemplazarlos con otros. ${ }^{77}$

Entre tanto, la provincia de origen de estos batallones siguió siendo requerida para nuevos reclutamientos como el que ordenó en este mes el presidente de las Provincias Unidas para formar una legión de emigrados de Socorro y Pamplona, cuerpo que estaría bajo el mando de José Antonio Ardila y que debía sumarse a la defensa del territorio ante el avance de la expedición militar española. ${ }^{78}$

Bajo este contexto, el gobierno de las Provincias Unidas, conciente de la amenazante superioridad militar española y de las sucesivas derrotas militares patriotas, ordenó en el mes de abril sacar de Popayán 500 fusiles y 300 soldados del batallón Socorro al mando del coronel Monsalve ${ }^{79}$ para que marcharan inmediatamente hacia

\footnotetext{
${ }^{76}$ En esta batalla fue herido Bibiano Salavarrieta, quien se había incorporado en 1815 al batallón Socorro y era hermano menor de la sacrificada Policarpa. Cacua, Custodio García 150.

${ }^{77}$ Riaño, Camilo, "La Independencia” 598.

${ }^{78}$ O'Leary, tomo XIV, 427.

${ }^{79}$ José Manuel Restrepo, Historia de la Revolución de la República de Colombia en la América Meridional (Medellín: Universidad de Antioquia-Universidad Nacional, 2009), 5a edición, tomo I, 415.
} 
Santa Fe con el fin reforzar la seguridad de este epicentro del poder político, quedando bajo las órdenes del coronel Manuel de Serviez. Con la partida de este cuerpo, el Ejército del Sur se redujo ostensiblemente a 700 hombres y, según el cronista José Hilario López, quedaron "privados del mejor cuerpo que teníamos entonces". ${ }^{80}$

Según relata en sus memorias el cadete Laureano López, los integrantes del batallón Socorro emprendieron su pausada marcha hacia la capital. A mediados de abril llegaron a la población de Funza, a pocas leguas de Santa Fe, y por estos días contaron con un apoyo de 500 pesos para los gastos necesarios. En los primeros días de mayo recibieron la orden superior de entrar a la capital en donde solo pernoctaron una noche para continuar el camino que pasaba por el puente del Común. Allí llegaron el 26 de abril para luego entrar a la parroquia de Chía donde se hallaba el entonces presidente de las Provincias Unidas don José Fernández de Madrid.

\section{El ocaso del batallón y la represión política}

Por estos días, cuando ya no quedaba ninguna esperanza de oponer resistencia a las fuerzas invasoras españolas, tanto el Presidente como los integrantes del Congreso republicano y los altos mandos militares discutían si concentraban la última resistencia en la sabana de Santa Fe o si se retiraban hacia el Sur o hacia los Llanos Orientales.

Al final, se ordenó al batallón Socorro que contramarchara hacia Popayán. ${ }^{81}$ El 3 de mayo de 1816, tres días antes de la llegada de Morillo a Santa Fe, Fernández de Madrid en compañía del general García Rovira y del batallón Socorro emprendieron la retirada hacia el $\mathrm{Sur}^{82}$ en momentos en que este cuerpo había mermado su pie de fuerza a la mitad a causa de las enfermedades y las continuas deserciones. Ya se sentía la persecución de las tropas del teniente coronel español Carlos Tolrá, comandante del Regimiento de Infantería de Numancia. El 10 de mayo arribaron cerca de la villa de Purificación en donde recibieron algunos hombres del batallón Veteranos para reemplazar las bajas, esto como fórmula de castigo a este cuerpo por traición a la causa patriota. ${ }^{83}$

Por instrucciones del presidente Fernández de Madrid, el 27 de mayo se ordenó al general García Rovira proteger la provincia de Neiva para lo cual había que prestar los auxilios necesarios y aumentar el pie de fuerza del batallón Socorro que se dirigía hacia aquella zona. El objetivo era reponer las bajas que este cuerpo había sufrido. ${ }^{84} \mathrm{Al}$ atardecer del 13 de junio se registró en el pueblo indígena de Natagaima una escaramuza entre las tropas del capitán español Juan Francisco Capdevila y el oficial Monsalve. Las huestes patriotas salieron en precipitada huida al ver la superioridad del oponente y fue tal el afán de Monsalve que huyó sin la silla de su

\footnotetext{
${ }^{80}$ López, tomo I, 79.

${ }^{81}$ O'Leary, tomo XIV, 535-541.

${ }^{82}$ Rodríguez, La antigua 296.

${ }^{83}$ Cacua, Custodio García 169.

84 “Otro", Gazeta de Santafé de Bogotá, capital del N. R. de Granada, No. 18, octubre 10 de 1816, 162-163.
} 
caballo. ${ }^{85}$ La tropa avanzó hasta Neiva en donde se contabilizaron varias huidas. ${ }^{86}$ En esta ciudad se llevó a cabo una cumbre de altos oficiales a la que asistieron Fernández de Madrid, García Rovira y Monsalve. Según el testimonio del militar Pedro Alcántara Herrán, ${ }^{87}$ un altercado ocurrido en esta ciudad entre el comandante accidental de la Guardia de Honor y el capellán del batallón Socorro, generó una división en estas fuerzas, disponiéndose la inmediata marcha del primero de estos cuerpos mientras que el segundo se quedó a retaguardia. Sin duda, estas fisuras acentuaron la debilidad del ejército patriota y sería una de las causas cruciales que explicarían las dos derrotas definitivas padecidas en los días siguientes. ${ }^{88}$

El brigadier Juan Sámano ocupó Popayán y con el respaldo de una columna de Pasto se movió hasta la Cuchilla del Tambo en donde el 29 de junio tendría lugar una de sus más cruentas batallas. En esta acción, los españoles tomaron prisioneros a la mayor parte de los oficiales republicanos quienes fueron remitidos a Popayán. ${ }^{89}$ Pese a haberse alzado con la victoria, Sámano decidió permanecer en máxima alerta ante el rumor de la inminente llegada de Monsalve y sus hombres. Sabedor de la bizarría de este oficial, hizo tocar la generala por todas las calles, preparó su tropa y mandó redoblar la seguridad de la cárcel. Esta era una prueba irrefutable de la dilatada fama alcanzada por el cuerpo de infantería guiado por aquel coronel socorrano.

Monsalve y el resto de tropa patriota llegaron a La Plata sin que hubiesen alcanzado a llegar los restos de las fuerzas vencidas en la Cuchilla del Tambo y, tras la información equivocada suministrada por un falso espía que hacía vigilancia en los alrededores, el teniente coronel Tolrá irrumpió sorpresivamente el 10 de julio en esta localidad. De manera valerosa, Monsalve y sus hombres se vieron avocados a enfrentar una bien equipada columna de 700 soldados españoles. ${ }^{90}$

En esta batalla, las huestes españolas atacaron con sus cuerpos Cazadores, Granaderos y $3^{a}$ Compañía a las órdenes del oficial Capdevila que distrajeron las tropas republicanas mientras Tolrá atacaba por la espalda después de atravesar el río que bordea esta población. Los republicanos huyeron dispersados por los montes, dirigiéndose algunos hacia el camino de Popayán. Tolrá guardaba la esperanza de capturar a Monsalve, para lo cual había enviado la $4^{a}$ Compañía por esta vía, aunque al final solo lograron sorprender a unos cuantos soldados derrotados. Tras el combate, los españoles reportaron 56 prisioneros y más de 60 muertos, además de otros que fueron arrojados al río. ${ }^{91}$

\footnotetext{
${ }^{85}$ Boletín del Exército Expedicionario, No. 30, junio 23 de 1816, 1.

${ }^{86}$ Prado y Prado 66.

${ }^{87}$ Este militar ascendería años más tarde a General y luego ocuparía la Presidencia de la República.

${ }^{88}$ Rodríguez, La antigua, 296-297; Rebecca A. Earle, España y la Independencia de Colombia, 1810-1825 (Bogotá: Ediciones Uniandes-Banco de la República, 2104) 84.

${ }^{89}$ Boletín del Exército Expedicionario, No. 34, julio 27 de 1816, 1-2.

${ }^{90}$ José María Baraya, Biografías militares o historia militar del país en medio siglo (Bogotá: Imprenta de Gaitán, 1874) 35-36.

${ }^{91}$ Boletín del Exército Expedicionario, No. 33, julio 18 de 1816, 2; Gazeta de Santafé, No. 2, junio 20 de
} 
Pese a su resistencia, Monsalve perdió el combate debido a las reducidas municiones y la notoria desigualdad de fuerzas. Fue prácticamente el aniquilamiento del batallón Socorro, siendo el último en sucumbir ante la invasión española. En esta acción militar cayeron presos el alférez Vanegas y Laureano López, el abanderado de dicho batallón quien era hermano del militar y cronista José Hilario López. Finalmente, Monsalve abandonó el campo de batalla y buscó refugio en las cimas de la cordillera, pero allí fue capturado tras ser traicionado por algunos patianos a quienes había pedido protección. Muy cerca de allí también cayó preso el general García Rovira. ${ }^{92}$

Varios prisioneros de guerra salieron de La Plata el 30 de julio hacia Santa Fe para ser puestos a órdenes del comandante Pablo Morillo. Al cabo de unos meses, algunos de ellos serían indultados y otros fueron obligados a servir en el ejército realista. ${ }^{93}$ Con estos fracasos militares prácticamente quedó abatido el Ejército del Sur mientras que los españoles veían cristalizado su propósito de pacificar en un corto tiempo todas las provincias de la Nueva Granada, a excepción de Casanare en donde se empezaba a concentrar la resistencia insurgente.

Días después de su derrota en La Plata, Monsalve fue conducido a Santa Fe y luego a su natal Socorro en donde, con el fin de causar mayor escarmiento, fue fusilado por la espalda el 3 de septiembre en la plaza de aquella villa por orden expresa del general Morillo. La ejecución se hizo al lado de su hermano Juan José, ${ }^{94}$ quien lo había acompañado a lo largo de estos tres años de campaña militar. Otros, como el coronel Emigdio Troyano y el exgobernador José Antonio Ardila Plata, también subieron al cadalso. Ese mismo día, el cura de la villa don Francisco García les dio a estos hombres cristiana sepultura. ${ }^{95}$ Pocas semanas después, el gobierno de Reconquista publicó el listado de los rebeldes sometidos al Consejo de Guerra Permanente, dentro de los cuales quedó consignado el perfil del oficial Monsalve como "[...] enemigo acérrimo de la causa del Soberano y bien conocido por sus crímenes, en cuyo sistema se mantuvo obstinado hasta los últimos momentos de la independencia". ${ }^{96}$

En los meses siguientes, los altos mandos españoles asentados en Santa $\mathrm{Fe}$ trabajaron articuladamente con las autoridades del Socorro para acentuar la persecución de aquellos que habían hecho parte del batallón. El 11 de julio el gobernador español de esta provincia Antonio Fominaya reportó a sus superiores la captura de Luis Otero, subteniente de aquel cuerpo. El 7 de agosto Morillo solicitó a Fominaya averiguar el

\footnotetext{
$1816,15$.

92 Espinosa 142; López, tomo I, 90-92; “Autobiografía” 545.

${ }^{93}$ Prado y Prado 71.

${ }^{94}$ Durante ese tiempo, sus otros hermanos Nicolás y José Antonio también fueron llevados al patíbulo en Neiva y Bogotá respectivamente. Paulo Forero, Las heroínas olvidadas de la Independencia (Bogotá: Ministerio de Educación Nacional, 1972) 15.

${ }^{95}$ Espinosa 128-129; Scarpetta y Vergara 340; Rodríguez, La antigua, 367, 370.

${ }^{96}$ Relación de las principales cabezas de la rebelión de este Nuevo Reyno de Granada (Santafé: Imprenta del Gobierno por Nicomedes Lora, 1816) 4.
} 
paradero de 35 militares del batallón que, según informaciones confiables, se hallaban escondidos en esta provincia. Esto en razón a que se había vencido el plazo fijado por el indulto ${ }^{97}$ decretado tres meses atrás por el gobierno español y ninguno de aquellos excombatientes se había presentado. En la lista figuraban 11 capitanes, 10 tenientes y 11 subtenientes. ${ }^{98}$

\section{Conclusiones y reflexiones}

Al momento de analizar las causas de la frustrada Campaña del Sur, debe necesariamente mencionarse la configuración misma de las fuerzas que se habían mezclado en el Ejército de la Unión, una amalgama de representaciones regionales que en cierta medida reflejaban la composición política de las Provincias confederadas, cada una de ellas con sus propios intereses e influenciadas por las disputas intestinas entre centralistas y federalistas. Hombres provenientes de Santa Fe, Tunja, Socorro, Pamplona, Antioquia, Neiva, Popayán y otras regiones más, una compleja suma de combatientes en la que no fue posible lograr una cohesión de conjunto. En cierta medida, los efectos negativos de esta falta de homogeneidad repercutieron en el desenlace de la campaña. ${ }^{99}$

La frágil tregua entre centralistas y federalistas fue muy tardía, circunstancial y susceptible de desconfianzas sin que se olvidaran del todo los intereses políticos partidistas. Todo esto, sin duda, se constituyó en un factor perturbador para el propósito común de expulsar a los últimos reductos españoles. A través de la trayectoria del batallón Socorro en sus tres años de existencia es posible examinar el impacto de este complejo trasfondo político de la primera República federativa. Es por ello de que este cuerpo se vio permeado por la polarización interna. Sin embargo, pese a todas las vicisitudes, siguió manteniendo su pie de fuerza y su nominación de origen provincial, como una reafirmación de su filiación federalista, aunque ya en el transcurso de la campaña debió ser reforzado por reclutas provenientes de otras provincias, especialmente del Sur.

Tanto sus compañeros de lucha como sus adversarios reconocieron la valentía de este batallón. Memorable fue su habilidosa operación en Juanambú, un recordatorio de lo que sería la obstinada resistencia que tendrían que enfrentar las fuerzas republicanas durante las repetidas ofensivas lanzadas después de la batalla de Boyacá del 7 de agosto de 1819 en su afán por conquistar las ciudades de Pasto y Quito. ${ }^{100}$ Fue este un batallón que se ganó la confianza de los altos mandos militares

\footnotetext{
${ }^{97}$ Este indulto firmado por Morillo el 24 de abril de 1816 cobijó a los sargentos, cabos y soldados que hubiesen servido al gobierno "rebelde" a quienes se extendió la invitación para que depusieran sus armas y se entregaran. Pablo Morillo, Indulto (Santafé: Imp. Del Gobierno por Nicomedes Lora, 1816) 1. Tomado de: BNC, Fondo Pineda, tomo 854.

${ }^{98}$ Rodríguez, La antigua 364.

99 Thibaud 172.

${ }^{100}$ Roberto Cortázar, (Comp.), Cartas y mensajes del General Francisco de Paula Santander (Bogotá: Academia Colombiana de Historia, 1956), Vol. II, 62. Sobre la dificultad de las operaciones militares en el paso de Juanambú véase: José Hilario López, Memorias (Bogotá: Editorial ABC, 1942), tomo I, 46-50.
} 
del Ejército del Sur y exhibió una gran dinámica y una capacidad adaptativa que le permitió desenvolverse en varios frentes y posiciones de combate, méritos estos que les permitieron a varios de sus miembros rápidos ascensos en el escalafón militar.

En esta investigación queda también en evidencia el liderazgo del coronel Pedro Monsalve al lograr posicionar a su batallón en estos primeros años de lucha militar, con lo cual se pone de relieve la necesidad de rescatar el papel asumido por los mandos medios en las guerras de Independencia con miras a que se les visibilice dentro del marco del desarrollo histórico regional. ${ }^{101}$ Era tal el protagonismo y el reconocimiento de la valentía de este oficial, que el militar Antonio Obando cuando hacía referencia al batallón Socorro, lo llamaba batallón Monsalve. ${ }^{102}$

Desafortunadamente, las fuentes documentales disponibles no permiten hacer un seguimiento exhaustivo a los caminos que tomaron los pocos soldados patriotas que sobrevivieron a la campaña de represión liderada por el virrey Juan Sámano y el comandante Pablo Morillo. Algunos de los que cayeron prisioneros en la Cuchilla del Tambo, en La Plata y en otras batallas fueron obligados a incorporarse en calidad de soldados rasos en las fuerzas realistas ante la creciente demanda de pie de fuerza, aunque, según lo revelado por los informes de los oficiales españoles, este tipo de reclutas forzados resultaron bastante propensos a la deserción debido a sus débiles vínculos de lealtad hacia el Rey. ${ }^{103}$ Otros eventualmente ingresaron a las guerrillas que operaron en 1818 y 1819 en las provincias de Socorro y Tunja, después de lo cual participaron en la batalla de Boyacá y en la última fase de liberación. Se sabe por lo menos que buena parte del batallón Cazadores de la Nueva Granada, uno de los cuerpos que emprendieron la Campaña Libertadora, estaba conformado por veteranos neogranadinos provenientes del área andina sobrevivientes de la lucha militar vivida en la primera fase republicana. ${ }^{104}$

En los fondos Hojas de Servicio y Secretaría de Guerra y Marina del Archivo General de la Nación se puede rastrear de manera detallada la trayectoria de algunos de estos militares que, en calidad de veteranos, continuaron brindando su aporte a la lucha emancipadora. Un primer ejemplo de ello fue el teniente socorrano José Antonio Vega, quien participó a sus 27 años en las acciones de Calibío, Juanambú, Tacines y en Pasto donde fue capturado por los realistas. Al recuperar en 1819 los republicanos el

\footnotetext{
${ }^{101}$ Actualmente en el municipio de El Socorro se conserva una estatua y una placa en homenaje a este oficial de la Independencia. Luis Rubén Pérez Pinzón, "El patrimonio monumental Bicentenario y la ruta turística «Libertadora»”, La Tercera Orilla 21 (2018): 113.

102 "Autobiografía” 544.

${ }^{103}$ Oswaldo Díaz Díaz, "Contribuciones de las guerrillas a la Campaña Libertadora 1817-1819”, en: Historia Extensa de Colombia (Bogotá, Ediciones Lerner), 1967, Vol. VI, tomo 2, 273.

Jorge Conde Calderón, "Las pugnas entre centralistas y federalistas", en: Historia de la Independencia de Colombia. Revolución, Independencias y guerras civiles (Bogotá: Presidencia de la República), 2010, tomo I, 92.

Espinosa 85.

${ }^{104}$ José Roberto Ibáñez Sánchez, Campaña Libertadora de la Nueva Granada de 1819 (Tunja: Academia Boyacense de Historia) 200953.
} 
poder, Vega empuñó las armas en la villa de Purificación y colaboró en la persecución de los enemigos hasta la población de La Plata. Luego se incorporó al batallón Vargas y se trasladó hasta Mompós y allí luchó en las batallas del bajo Magdalena y en la toma de la ciudad de Ocaña en donde enfermó, razón por la cual solicitó en septiembre de 1823 el retiro del servicio militar. ${ }^{105}$

Finalmente, vale resaltar la exitosa trayectoria militar de Vicente Vanegas, oriundo de la ciudad de Vélez, quien estuvo presente en los campos del Sur desde la batalla del Alto Palacé hasta el combate ocurrido en La Plata en 1816. Tras ascender al grado de teniente coronel, fue enrolado entre 1817 y 1819 a las guerrillas patriotas bajo las órdenes de los oficiales José Antonio Páez y Simón Bolívar en los llanos venezolanos. En los años siguientes ocupó importantes cargos, dentro de los cuales cabe mencionar: comandante de armas de las provincias de Mariquita, Socorro y Tunja, ministro de la Alta Corte Marcial y en 1835 se desempeñó como ayudante subjefe del Estado Mayor de la República. ${ }^{106}$

Si bien la Campaña del Sur no logró su objetivo, lo que vale resaltar es cómo este ejército se constituyó en la principal base de formación de milicias republicanas que, como en el caso del batallón Socorro, a través de un recorrido intenso de más de 500 leguas pudieron adquirir experiencia y demostrar que sí era posible enfrentar a las huestes realistas, siendo la semilla para el establecimiento de batallones ${ }^{107}$ más estructurados que contribuirían a alcanzar la independencia definitiva, esta vez sin las interferencias políticas internas experimentadas en la primera fase republicana.

Complementariamente al aporte de estos veteranos, la provincia del Socorro continuó suministrando ininterrumpidamente recursos y pie de fuerza ${ }^{108}$ destinados no solo a consolidar la libertad de la Nueva Granada sino a proseguir la ofensiva en Venezuela, Quito y Perú, una constatación más de su indeclinable voluntad de apoyo a la causa independentista.

\section{Bibliografía}

\section{Fuentes Primarias}

\section{Archivos}

Archivo General de la Nación (AGNC). Bogotá-Colombia. Sección República, Fondo Hojas de Servicio.

\footnotetext{
${ }^{105}$ AGN, Sección República, Fondo Hojas de servicio, tomo 45, f. 722r.

${ }^{106}$ AGN, Sección República, Fondo Hojas de servicio, tomo 47, f. 325r.

${ }^{107}$ Los cálculos indican que para 1820 existían ya 20 batallones republicanos en acción. Thibaud, 455-496.

${ }^{108}$ En noviembre de 1821, por ejemplo, el general Bolívar ordenó a las provincias de Pamplona, Tunja, Socorro y Bogotá enrolar 2.000 hombres para reparar las pérdidas de los batallones y restituir las fuerzas iniciales. Roberto Cortázar (Comp.), Correspondencia dirigida al General Santander (Bogotá: Academia Colombiana de Historia, 1969), Vol. XII, 282; Thibaud 321.
} 
Archivo Central del Cauca (ACC). Popayán-Colombia. Sala Independencia.

Archivo Histórico Restrepo (AHR). Bogotá-Colombia. Fondo I, Vol. 18.

Biblioteca Nacional de Colombia (BNC). Bogotá-Colombia. Fondos Cuervo, Pineda.

\section{Publicaciones periódicas}

Argos de la Nueva Granada, Santa Fe, 1815.

Gazeta de Santafé, capital del N. R. de Granada, Santa Fe, 1816.

Gazeta Ministerial de Cundinamarca, Santa Fe, 1813-1815.

\section{Fuentes primarias impresas}

“Autobiografía de Antonio Obando". Boletín de Historia y Antigüedades, VIII.93 (1913).

Arroyo, Santiago. Apuntes históricos sobre la revolución de la Independencia de Popayán, en: BNC, Fondo Cuervo, tomo 1.377.

Aymerich, Melchor. Diario de Operaciones del Exército Real. Lima: Imprenta de los huérfanos por D. Bernardino Ruíz, 1814.

Boletín del Exército Expedicionario. Santafé: En la imprenta del Gobierno por Nicomedes Lora, 1816.

Caballero, José María. Particularidades de Santafé. Bogotá: Academia Colombiana de Historia, 1989.

González, Florentino. Memorias. Medellín: Editorial Bedout, 1971.

Campo Larraondo, Manuel Mariano del. Rasgos poéticos que pueden servir de apuntamientos sobre la historia de nuestra revolución. Chía: Universidad de La Sabana, 2012.

Castrillón Arboleda, Diego. Manuel José Castrillón. Biografía y Memorias. Bogotá: Banco Popular, 1971, tomo I.

Colmenares, Germán (Comp.). Relaciones e Informes de los Gobernantes de la Nueva Granada. Bogotá: Biblioteca Banco Popular, 1989, tomo III. 
La travesía del batallón Socorro en la Campaña del Sur: legado de un batallón provincial...

Cortázar, Roberto (Comp.). Cartas y mensajes del General Francisco de Paula Santander. Bogotá: Academia Colombiana de Historia, 1956, Vol. II.

Cortázar, Roberto (Comp.). Correspondencia dirigida al General Santander. Bogotá: Academia Colombiana de Historia, 1969, Vol. XII.

Espinosa, José María. Memorias de un abanderado. Bogotá: Banco Popular, 1971.

Hernández de Alba, Guillermo (Comp.). Archivo Nariño. Bogotá: Biblioteca de la Presidencia de la República, 1990, tomo IV.

Ibáñez, Pedro M. Crónicas de Bogotá. Bogotá: Biblioteca Popular de Cultura Colombiana, 1951, tomo III.

López, José Hilario. Memorias. Bogotá: Editorial ABC, 1942, tomo I.

Morillo, Pablo. Indulto. Santafé: Imp. Del Gobierno por Nicomedes Lora, 1816.

O'Leary, Simón. Memorias del General O'Leary. Caracas: Imprenta de la Gaceta Oficial, 1983, tomos XIII-XIV.

Ortiz, Sergio Elías. Colección de documentos para la historia de Colombia. (Época de la Independencia). Bogotá: Academia Colombiana de Historia, 1964.

Osorio, Alejandro. “Campaña de Nariño en el Sur”. Boletín de Historia y Antigüedades, 96 (1913): 735-746.

Posada, Eduardo (Comp.). Congreso de las Provincias Unidas. Bogotá: Imprenta Nacional, 1924.

Perú de la Croix, Luis. Diario de Bucaramanga. Cali: Fundación para la Investigación y la Cultura, 1999.

Prado Arellano, Luis Ervin y David Fernando Prado Valencia. Laureano López y Joaquín Mosquera. Recuerdos de dos payaneses sobre la guerra de Independencia y la disolución de Colombia. Bucaramanga: Universidad Industrial de Santander, 2012.

Relación de las principales cabezas de la rebelión de este Nuevo Reyno de Granada. Santafé: Imprenta del Gobierno por Nicomedes Lora, 1816.

Restrepo, José Manuel. Historia de la Revolución de la República de Colombia en la América Meridional. Medellín: Universidad de Antioquia-Universidad Nacional, $2009,5^{\text {a }}$ edición, tomo I. 
Rodríguez Plata, Horacio. La antigua provincia del Socorro y la Independencia. Bogotá: Academia Colombiana de Historia, 1963.

Rodríguez Villa, Antonio. El teniente general don Pablo Morillo. Primer Conde de Cartagena, Marqués de la Fuerte (1778-1837). Madrid: Tipografía de Fortanet, 1910, tomo I.

Samper, José María. Ensayo sobre las revoluciones políticas. Bogotá: Universidad Nacional de Colombia, 1969.

Scarpetta, Leonidas y Saturnino Vergara. Diccionario biográfico de los campeones de la libertad de Nueva Granada, Venezuela, Ecuador i Perú. Bogotá: Imprenta de Zalamea, 1879.

\section{Fuentes secundarias}

\section{Libros}

Alemán, Isidro. Apuntes para la historia del batallón Matamoros de Morelia. Morelia: Universidad Michoacana, 1997.

Andrade, Alberto. José María Cabal. Prócer de la Independencia. Bogotá: Imprenta de las Fuerzas Militares, 1973.

Arango Collazos, Otoniel. Batallón de Artillería No. 8 Batalla de San Mateo. Bogotá: Escuela Militar José María Córdova, 2013.

Baraya, José María. Biografías militares o historia militar del país en medio siglo. Bogotá: Imprenta de Gaitán, 1874.

Batalla de Calibío. Popayán: Ejército Nacional, 1975.

Cacua Prada, Antonio. Custodio García Rovira: el estudiante mártir. Bogotá: Academia Colombiana de Historia, 1983.

Cacua Prada, Antonio. Yo soy Nariño. Bogotá: Editora Guadalupe, 2008.

Cox, Patricia. Batallón de San Patricio. México D.F.: San Jerónimo Editores, 1999.

Domínguez Loyo, Miguel. El batallón expedicionario de Asturias y su comandante don Juan de Cándano: episodios de la guerra de Independencia. México D.F.: Editorial Citlaltepetl, 1964.

Earle, Rebecca A. España y la Independencia de Colombia, 1810-1825. Bogotá: Ediciones Uniandes-Banco de la República, 2104. 
La travesía del batallón Socorro en la Campaña del Sur: legado de un batallón provincial...

Forero, Paulo. Las heroínas olvidadas de la Independencia. Bogotá: Ministerio de Educación Nacional, 1972.

Herrero Fernández-Quesada, María Dolores. "La investigación en historia militar de la Edad Moderna y sus fuentes", Cuadernos de Historia Moderna 38 (2013): 165214.

Ibáñez Sánchez, José Roberto. Campaña Libertadora de la Nueva Granada de 1819. Tunja: Academia Boyacense de Historia, 2009.

Kuethe, Allan J. Reforma militar y sociedad en la Nueva Granada, 1773-1808. Santafé de Bogotá: Banco de la República, 1993.

Negret, Rafael. Campaña del Sur del General Don Antonio Nariño, 1813-1814. Bogotá: Imprenta del Estado Mayor General, 1919.

Phelan, John. El pueblo y el Rey. Revolución Comunera en Colombia, 1781. Bogotá: Carlos Valencia editores, 1980.

Riaño, Camilo. La batalla de Cachirí, Bogotá, Imprenta y Publicaciones de las Fuerzas Militares, 1966.

Riaño, Camilo. La batalla de Río Palo. Bogotá: Academia Colombiana de Historia, 1960.

Riaño, Camilo. La batalla del Juanambú. Bogotá: Imprenta Fuerzas Militares, 1965.

Ruíz Novoa, Alberto. El batallón Colombia en Corea. Bogotá: Empresa Nacional de Publicaciones, 1956.

Semprún, José y Alfonso Bullón de Mendoza. El ejército realista en la Independencia americana. Madrid: Editorial Mapfre, 1992.

Thibaud, Clément. Repúblicas en armas. Los ejércitos bolivarianos en la guerra de Independencia en Colombia y Venezuela. Bogotá: Planeta-Ifea, 2003.

\section{Capítulos de libros}

Conde Calderón, Jorge. "Las pugnas entre centralistas y federalistas". Historia de la Independencia de Colombia. Revolución, Independencias y guerras civiles, tomo I. Bogotá: Presidencia de la República, 2010.

Díaz Díaz, Oswaldo. "Contribuciones de las guerrillas a la Campaña Libertadora 18171819”, en: Historia Extensa de Colombia, Vol. VI, tomo 2. Bogotá: Ediciones Lerner, 1967. 
Mejía Argüello, Jairo Emilio. "Arquetipos y paradigmas históricos en los militares colombianos. Exploración desde la Conquista al siglo XXI". De milicias reales a militares contrainsurgentes. La institución militar en Colombia del siglo XVIII al XXI. Torres del Río, César y Saúl Rodríguez Hernández. Bogotá: Editorial Pontificia Universidad Javeriana, 2008.

Riaño, Camilo. "La Independencia (1810-1815)". Historia Extensa de Colombia, Vol. XVIII [Historia Militar], tomo 1, Bogotá: Ediciones Lerner, 1971.

Valencia Tovar, Álvaro. "La Colonia". Historia de las Fuerzas Militares de Colombia, tomo I. Bogotá: Editorial Planeta, 1993.

\section{Artículos en revistas}

Borreguero Beltrán, Cristina. "La historia militar en el contexto de las nuevas corrientes historiográficas. Una aproximación". Manuscrits. Revista d'História Moderna 34 (2016): 145-176.

Martínez, Enrique. "El batallón Pichincha”. Boletín de Historia y Antigüedades 230 (1933): 262-265.

McFarlane, Anthony. "La fragmentación del orden político: la "Primera República" en la Nueva Granada, 1810-1815”. Historia y Sociedad 8, (2002): 47-82.

Pérez Pinzón, Luis Rubén. "El patrimonio monumental Bicentenario y la ruta turística «Libertadora»". La Tercera Orilla 21 (2018): 108-115.

Pérez Pinzón, Luis Rubén. "Tergiversaciones sobre la batalla de Cachirí y el restablecimiento del régimen virreinal neogranadino (1816)". Historia y Memoria 15 (2017): 73-105.

Rodríguez Gómez, Juan Camilo. "La Independencia del Socorro en la génesis de la emancipación colombiana”. Credencial Historia 242 (2010): 1-6. 